\title{
Formação Profissional no SUS: o Papel da Atenção Básica em Saúde na Perspectiva Docente
}

\section{PALAVRAS-CHAVE \\ - Ensino. \\ - Aprendizagem. \\ - Sistema Único de Sáude. \\ - Educação em Saúde. \\ - Atenção Primária à Saúde.}

\section{KEYWORDS}

- Teaching.

- Learning.

- Single Health System.

- Health Education.

- Primary Health Care.

Recebido em: 16/12/2008

Reencaminhado em: 03/09/2009

Aprovado em: 27/10/2009

\section{Medical Training in the Single Health System in Brazil: The Role of Primary Healthcare from the Perspective of Medical Professors}

Ricardo Corrêa Ferreira Vânia Maria Lopes Fiorini ${ }^{I}$ Everton Crivelaro

\section{RESUMO}

A educação médica tem sofrido profundas críticas quanto à necessidade de diversificar os cenários de ensino-aprendizagem para que se construam novos currículos e sujeitos, possibilitando-lhes a inserção num processo pedagógico reflexivo e dinâmico. O objetivo desta pesquisa é analisar a percepção que docentes da Unidade de Prática Profissional da Faculdade de Medicina de Marília têm acerca do papel que a Atenção Básica de Saúde (ABS) desempenha na formação profissional dos estudantes. Realizou-se um estudo qualitativo por meio de grupos focais com análise de discurso dos sujeitos entrevistados. Construíram-se três categorias: o papel da ABS na construção do SUS; o papel do SUS na formação profissional de novos sujeitos; o papel docente na construção profissional de novos sujeitos. Considera-se fundamental o papel exercido pela ABS na formação dos profissionais de saúde, notadamente profissionais críticos e reflexivos, destacando-se o papel transformador e emancipador que o docente exerce nessa formação.

\section{ABSTRACT}

Medical education in Brazil has received serious criticism over the need to diversify teaching and learning environments, in order to develop new curricula and protagonists, allowing them to participate in a reflective and dynamic pedagogical process. The aim of the current study was to analyze the perceptions of professors at the Professional Practice Unit of the Marilia School of Medicine concerning the role of primary healthcare in students' professional training. A qualitative study was performed using focus groups and discourse analysis. Three categories were identified: the role of primary care in building the Single Health System; the role of the Single Health System in training new professionals; and the role of faculty in the professional development of new professionals. Primary healthcare plays a critical role in health professionals' training (especially that of critical and reflective professionals), with particular emphasis on medical professors' transforming and emancipative role. 


\section{INTRODUÇÃO}

Inúmeras mudanças sociais, éticas, econômicas e políticas observadas em âmbito mundial atingem de modo incisivo os sistemas de saúde1. Em nosso país, a saúde vem passando por um significativo processo de reforma social e política, cuja ação é fundamental à continuidade e ao avanço do movimento da Reforma Sanitária, bem como à construção efetiva do SUS. Por isso, vários segmentos do SUS devem cumprir um papel condutor de mudanças no campo tanto das práticas de saúde, como da formação profissional².

No setor do ensino, torna-se necessário semelhante movimento para uma reforma que expresse o atendimento dos interesses públicos no cumprimento das responsabilidades de formação acadêmico-científica, ética e humanística com vistas ao desempenho tecnoprofissional na área da saúde ${ }^{3}$.

O SUS, assim, tem assumido papel ativo na reorientação das estratégias de cuidado, tratamento e acompanhamento da saúde individual e coletiva, e é neste mesmo sentido que se apresenta a necessidade de rever os modos de formação para se atuar neste sistema de saúde.

\section{Os sujeitos e sua formação para o SUS}

Nas últimas décadas, o ensino superior em saúde, notadamente o ensino médico, tem sido alvo de profundas críticas quanto à sua capacidade de cumprir as finalidades gerais de seus programas, de desenvolver no estudante o potencial intelectual, o julgamento, a avaliação crítica, a abordagem criativa de análise e o raciocínio crítico ${ }^{4}$.

Uma proposta transformadora dos processos de formação e organização dos serviços seria alicerçada numa adequada articulação entre o sistema de saúde, suas várias esferas de gestão e as instituições formadoras. Tal proposta colocaria em evidência a formação para a área da saúde como construção da educação em serviço/educação permanente em saúde, agregando o desenvolvimento individual e institucional, os serviços, a atenção à saúde e o controle social ${ }^{3}$.

Surge, então, a noção de Quadrilátero da Formação, que articula os segmentos da formação, da atenção, da gestão e do controle social em saúde na proposição de dignificar as características locais, valorizar as capacidades instaladas, desenvolver as potencialidades existentes em cada realidade, estabelecer a aprendizagem significativa e crítica, bem como produzir sentidos, autoanálise e autogestão ${ }^{3}$.

Em referência à formação, esta proposta pretende mudar a concepção hegemônica tradicional (biologicista, mecanicista, centrada no professor e na transmissão) para uma concepção construtivista (problematizadora das práticas e dos saberes), incentivando a produção de conhecimento nos serviços.
Quanto à atenção, propõe-se construir novas práticas de saúde, tendo em vista os desafios da integralidade, da humanização e da cogestão junto aos usuários.

Quanto à gestão, espera-se configurar de modo criativo e original a rede de serviços, assegurar redes de atenção às necessidades em saúde e considerar na avaliação a satisfação dos usuários. Finalmente, quanto ao controle social, pretende-se verificar a presença dos movimentos sociais, ampliar as lutas por saúde e a construção do atendimento às necessidades sociais de saúde ${ }^{3}$.

Dessa maneira, é preciso implementar espaços de discussão, análise e reflexão das práticas no cotidiano do trabalho e dos referenciais que orientam essas práticas, por meio de apoiadores matriciais de outras áreas e ativadores de processos de mudança institucional ${ }^{5}$.

Entre a educação dos profissionais de saúde observa-se que a formação generalista é tradicionalmente pouco valorizada. No caso da medicina, desenvolveram-se inúmeras especialidades que provocaram um devastador impacto na organização da prática médica, fragmentando as intervenções e desestimulando a aquisição de conhecimentos científicos comuns ${ }^{6}$.

Na graduação, segundo Feuerwerker ${ }^{6}$, cada vez mais os conteúdos especializados permeiam os currículos, multiplicando-se disciplinas, conteúdos e tempos. Perdeu-se o conhecimento generalista das ações em saúde e substituiu-se cada vez mais o subjetivismo da relação profissional da saúde-paciente pela objetividade tecnológica das ciências da saúde.

No treinamento prático tradicional, os estudantes da saúde segregam teoria e prática, fragmentam o aprendizado, o que incentiva o crescimento das especializações existentes. Nas universidades, veem-se conteúdos sem relevância, hierarquização e desintegração do conhecimento, ao passo que ocorre uma enorme resistência às mudanças. Sair do hospital para trabalhar em outros cenários representa um grande desafio.

Assim, os futuros profissionais da saúde resistem a se aproximar de cenários que os distanciam do ideal de prática que cultivam: ser um profissional de hospital privado e de alto nível, ou trabalhar em consultório próprio ${ }^{6}$.

Em meio a este cenário de (de)formações, Piancastelli ${ }^{1}$ destaca a necessidade de mudança nos currículos dos cursos da área de saúde com conceitos e práticas relacionados ao planejamento, à promoção de saúde e à prevenção de doenças com a utilização de tecnologias eficazes e de metodologias de ensino-aprendizagem que vão além dos espaços acadêmicos e cheguem às realidades da população. Surge, logo, a necessidade de novos currículos nas práticas dos sujeitos. 


\section{Novos currículos e práticas dos sujeitos}

Verifica-se uma preocupação crescente com as mudanças na formação profissional em saúde, na qual cada vez mais se configura a necessidade de profissionais aptos a contribuir com a sociedade num contexto de profundas mudanças não somente em seu próprio campo profissional, mas também nos campos político e social ${ }^{4}$.

Em relação à formação médica, é preciso formar um profissional capaz de conduzir de forma autônoma seu processo de aprendizagem ao longo da vida profissional; capaz de se adaptar às mudanças, raciocinando criticamente e tomando decisões fundamentadas em sua própria avaliação; e com uma formação humanística que valorize a relação médico-paciente e o dever ético da profissão ${ }^{4}$

$\mathrm{Na}$ década atual, algumas iniciativas têm impulsionado mudanças no ensino médico brasileiro, tais como as Diretrizes Curriculares Nacionais7, o Programa de Incentivo às Mudanças Curriculares nos Cursos de Medicina (Promed) ${ }^{8}$ e o Programa Nacional de Reorientação da Formação Profissional em Saúde (Pró-Saúde) ${ }^{9}$.

Tais iniciativas apontam uma concepção diferenciada de educação, organizada em torno de quatro aprendizagens fundamentais que ao longo da vida seriam, para cada indivíduo, os pilares do conhecimento ${ }^{10}$ : "aprender a conhecer", que leva em conta as rápidas alterações provocadas pelo progresso científico e as novas formas de atividade econômica e social; "aprender a fazer", a fim de adquirir não somente uma qualificação profissional, mas, de maneira mais ampla, competências que tornem o sujeito apto a enfrentar as diferentes situações; "aprender a ser", para melhor desenvolver sua personalidade com autonomia, discernimento e responsabilidade pessoal; "aprender a viver juntos", de forma a desenvolver o conhecimento acerca dos outros e, a partir daí, criar um espírito novo que conduza à realização de projetos comuns.

Entretanto, é na prática profissional, centrada em cenários hospitalares, que, tradicionalmente, se têm desenvolvido os currículos médicos e de Enfermagem, nos quais a formação profissional da saúde ampliada, humanista e generalista não tem sido eficazmente estimulada. Assim, destaca-se a necessidade de diversificar os cenários de ensino-aprendizagem para a construção de novos currículos e sujeitos ${ }^{11}$.

\section{Diversificação dos cenários de ensino-aprendizagem}

A diversificação dos cenários é compreendida como uma das estratégias para a transformação curricular. Essa estratégia aproxima os estudantes da vida cotidiana da população e desenvolve um olhar crítico, possibilitando cuidar dos reais problemas da sociedade.
Cenários de aprendizagem não devem se restringir aos locais de desenvolvimento de práticas profissionais meramente preestabelecidas; devem, sim, representar espaços em que as relações dos sujeitos sejam eficazmente desenvolvidas, abrindo caminhos para a criatividade e as transformações; e possibilitar incorporar o estudante a um processo enriquecedor de produção do serviço, favorecendo fecundas construções em sua formação profissional ${ }^{11}$.

Uma das opções é a aprendizagem baseada na Atenção Básica em Saúde (ABS), na qual, segundo Campos ${ }^{12}$, a inserção do estudante desde o início do curso em atividades práticas propicia um campo potencial e necessário, condizente com a realidade vivenciada pela grande massa populacional brasileira, possibilitando ao estudante uma clínica ampliada dos saberes, a aplicação efetiva de ações preventivas e promotoras da saúde coletiva e a vivência do acolhimento à demanda, com avaliação da vulnerabilidade das pessoas e comunidades.

Diferentemente dos processos de formação que envolvem breves estágios em centros de saúde-escola, este tipo de educação requer envolvimento dos estudantes com e na comunidade, gerando reflexões sobre esta, a qual embasa a construção de sua aprendizagem. Tais processos educacionais requerem, naturalmente, um papel docente diferenciado para a melhor condução dessa formação ${ }^{13}$.

\section{O papel docente na construção da formação baseada na ABS}

A formação profissional dos estudantes da área da saúde necessita de uma estrutura que permita e facilite o trânsito entre teoria e prática. Neste contexto, os docentes devem ser mediadores fundamentais nesta relação, orientando e facilitando o processo de ensino-aprendizagem ${ }^{12}$.

Neste processo, a participação dos serviços de saúde, com seus profissionais desempenhando o papel de preceptores e supervisores de estudantes, contribui para a definição e organização das práticas dos estudantes e para o desenvolvimento conjunto de suas atividades.

A função do docente dá sustentação às atividades educativas que se iniciam com a familiarização do estudante com o novo processo pedagógico que passa a vivenciar. Esta prática educativa estimula o estudante a expor suas ideias, dúvidas, sentimentos, conhecimentos e valores, sem medo de ser ridicularizado, punido ou sofrer outras consequências tão comuns no ensino tradicional ${ }^{13}$.

Assim, o trabalho pedagógico deve fluir numa trajetória estimulante, que possibilite a construção de significados, o desenvolvimento de capacidades para o trabalho em saúde, o reconhecimento das próprias dificuldades e a elaboração de propostas para a superação destas. 
As atividades favorecem essa construção, já que, partindo de ações mais livres que consideram as capacidades prévias dos estudantes, se permite a aplicação dos métodos clínicos e epidemiológicos ao trabalho em saúde ${ }^{13}$. Surge, então, a necessidade de estruturas educacionais condizentes com esta nova estratégia de ensino-aprendizagem, como a Unidade de Prática Profissional desenvolvida na Faculdade de Medicina de Marília.

\section{A Famema e sua proposta de formação inovadora}

A partir de 2003, a Unidade de Prática Profissional (UPP) da Famema passou a contribuir para a formação diferenciada do profissional de saúde, estabelecendo desempenhos e atitudes compatíveis com as necessidades existentes em nossa sociedade.

Nessa formação, o estudante é motivado a se comunicar claramente e a desenvolver capacidades para um adequado trabalho em equipe, de modo a satisfazer as necessidades de saúde de pacientes, famílias e comunidade. $\mathrm{O}$ aluno participa da exploração de problemas e situações, trazendo consigo capacidades prévias (conhecimento, valores, representações e experiências) para a construção de novas propostas de aprendizagem, compatíveis com os hiatos identificados frente à compreensão da realidade onde está inserido ${ }^{13}$.

Buscam-se, então, informações, que são submetidas a análise crítica, discussão, articulação e integração. Posteriormente, volta-se para a aplicação destas em seu contexto, na Atenção Básica em Saúde. Dessa forma, constrói-se um currículo inovador em que a aprendizagem é individualizada e tem como objetivo estimular o estudante a desenvolver a capacidade de aprender a aprender a partir da realidade em que se insere ${ }^{13}$.

Com isso, coloca-se em prática a pedagogia crítica, em que se incorpora ao currículo a experiência acadêmica, compreendida como o entendimento e a resolução das contradições sociais e éticas que se vive ${ }^{14}$.

Nesta perspectiva, a UPP objetiva, no plano curricular da Famema, enfrentar esses desafios de formação dos profissionais de saúde, utilizando como cenário de prática - com aprendizagens diversificadas e condizentes com as situações reais vivenciadas pela comunidade mariliense - a situação de serviço, na Unidade de Saúde da Família (USF) ${ }^{15}$.

Portanto, a UPP favorece a instrumentação necessária à integralidade da aprendizagem dos estudantes já na primeira série.

Nesta unidade educacional, a interdisciplinaridade é vivenciada quando os estudantes trabalham juntos e com uma equipe de USF — estudantes de Enfermagem, agentes comunitários, médico e enfermeiro do serviço e/ou docentes médicos e enfermeiros, dentista, assistente social, psicólogo e auxiliares de enfermagem — na resolução de problemas e necessidades de saúde da comunidade da área de abrangência da USF.

Essa equipe elabora planos de ações em conjunto, o que propicia pesquisa-ação e diálogo de saberes com os diversos sujeitos. Tutores, consultores, profissionais de saúde vivenciam situações reais que desafiam para a discussão de princípios éticos e morais, bem como abordam diferenças históricas, culturais e sociais, permitindo a construção da integralidade da atenção à saúde ${ }^{13}$.

Destacamos a pertinência e a necessidade de dar voz e analisar a percepção de docentes da UPP, ativadores do processo de ensino-aprendizagem na formação profissional na ABS, a fim de compreender, por meio de seus discursos vivos, suas concepções acerca do significado desse tipo de aprendizagem na formação do profissional, contribuindo para o planejamento de ações que incrementem mudanças na graduação em saúde no Brasil.

\section{OBJETIVO}

Analisar a percepção de docentes médicos e enfermeiros da Unidade de Prática Profissional da primeira e segunda séries da Famema acerca do papel que a Atenção Básica de Saúde (ABS) desempenha na formação profissional de estudantes de Medicina e Enfermagem dessa instituição, no contexto do SUS.

\section{MATERIAL E MÉTODOS}

\section{População e sujeitos}

Esta pesquisa foi realizada por meio de um estudo qualitativo sobre a percepção de docentes médicos e enfermeiros, participantes da UPP da primeira e segunda séries da Famema, acerca do papel da ABS na formação profissional de estudantes de Medicina e Enfermagem.

Escolheu-se a abordagem qualitativa por ser a mais adequada à análise das percepções, expectativas e valores desses docentes frente à formação profissional na $\mathrm{ABS}^{16}$. Esse tipo de estudo analisa e classifica processos dinâmicos vividos por grupos sociais e compreende o comportamento dos fatos, envolvendo maior interesse pelos significados do que pela frequência com que estes ocorrem ${ }^{17}$.

O campo de estudo caracterizou-se pelo contexto onde se desenvolve a UPP, ou seja, o espaço de desenvolvimento da UPP das duas primeiras séries dos cursos de Medicina e Enfermagem da Famema, o contexto da área de abrangência de 20 USFs, em Marília (SP). As atividades nestes cenários reais de prática profissional são realizadas por 20 grupos de estudantes (10 grupos da primeira série e 10 grupos da segunda série); cada grupo é composto por 8 estudantes de Medicina e 4 de Enfermagem, sob a coordenação de uma dupla de professores, sendo um médico e um enfermeiro. 


\section{Aspectos éticos e procedimentos de coleta}

Esta pesquisa, atendendo aos procedimentos previstos na Resolução 196/96 do Conselho Nacional de Saúde, foi aprovada pelo Comitê de Ética em Pesquisa (CEP) da instituição em que foi desenvolvida (Protocolo de Estudo do CEP da Famema no 226/06). Foi financiada pelo Programa de Bolsas Científicas Promed-Famema e não houve conflito de interesses dos autores.

Esta investigação abrangeu um universo de 40 docentes, sendo 10 médicos e 10 enfermeiros da UPP1 (primeira série), e 10 médicos e 10 enfermeiros da UPP2 (segunda série). Para compor os dois grupos focais, foram sorteados sujeitos de forma aleatória, representativa e intencional. Os grupos foram compostos por 20 docentes, selecionando-se 5 médicos e 5 enfermeiros da UPP1, bem como 5 médicos e 5 enfermeiros da UPP2. Estes sujeitos foram separados de acordo com a série em que estavam inseridos e, compondo um grupo de 10 docentes da UPP1 e outro grupo de 10 docentes da UPP2, convidados a participar dos grupos.

Na coleta dos dados foi utilizada a técnica de grupo focal, que consiste numa entrevista em grupo, baseada em um tópico a ser explorado e focalizado pelo grupo.

No início de cada grupo focal foi apresentado seu objetivo, proposto um termo de compromisso, garantindo o sigilo da pesquisa, e obtido o consentimento dos participantes. O pesquisador utilizou as seguintes perguntas norteadoras da discussão: (a) Qual o significado, para vocês, da Atenção Básica em Saúde na construção do SUS?; (b) Como vocês acham que a Atenção Básica em Saúde pode contribuir para a formação de futuros profissionais de saúde?; (c) Como vocês auxiliam no processo de ensino-aprendizagem destes estudantes na Atenção Básica em Saúde?

\section{Forma de análise dos resultados}

Os dados coletados foram analisados pelo método proposto por Minayo ${ }^{18}$. Segundo a autora, na análise estamos em busca dos significados manifestos e latentes do material coletado por meio dos discursos das pessoas.

Alguns dos passos para operacionalizar a técnica foram: (a) organização dos dados com a transcrição das fitas cassete e releitura do material (ou leitura flutuante), organizando-o em determinada sequência; (b) ordenação dos dados, realizando uma leitura exaustiva e repetida dos textos, com a constituição de um ou vários corpus, e detecção dos núcleos de sentido; (c) análise final, por meio de triangulação com o referencial teórico e o material coletado.

Cada docente será representado da seguinte forma: docente médico da UPP1: M1P1, M2P1... M5P1; da UPP 2: M1P2,
M2P2... M5P3; docente enfermeiro da UPP1: E1P1, E2P1... E5P1; e da UPP2: E1P2, E2P2... E5P2.

\section{DISCUSSÃO DOS RESULTADOS}

A análise dos dados permitiu a construção de três categorias empíricas: o papel da Atenção Básica em Saúde na construção do SUS sob a ótica docente; o papel do SUS na formação profissional de novos sujeitos; o papel docente na construção profissional de novos sujeitos.

Cada uma das categorias será abordada a seguir.

\section{O papel da Atenção Básica em Saúde na construção do SUS sob a ótica docente}

Ao longo do tempo, a prática clínica centrada na dimensão de cuidado foi substituída pelo ato prescritivo e resumido da relação profissional-usuário, construída pela clínica centrada no biológico e impulsionada pelo complexo médico-industrial do século 20, composto por alto consumo de máquinas, instrumentos, medicamentos e caros recursos diagnósticos e terapêuticos ${ }^{19}$.

Em contrapartida, o Programa de Saúde da Família (PSF) tem sido, desde então, a principal resposta oferecida ao pragmatismo tecnoassistencial vivido pela saúde contemporânea, assentada na visão biologicista do processo saúde-doença, hospitalocêntrica e voltada para ações "curativas". A atenção dada pelo PSF centra-se na família, entendida e percebida a partir de seu ambiente físico e social, e possibilita a seus profissionais uma compreensão melhor do processo saúde-doença $^{20}$, como declara um entrevistado:

O Programa de Saúde da Família vem substituir um modelo que não estava dando respostas e consegue trazer um cuidado mais eficaz, porque aborda necessidades fundamentais e faz o cuidado integral. (E3P1)

Desta forma, para que a prática em saúde responda aos princípios da integralidade preconizados pelo SUS na Atenção Básica em Saúde, a linha de cuidado em saúde deve ser fruto de uma grande pactuação entre os atores envolvidos nos serviços e recursos assistenciais, centralizando o usuário no processo de produção de saúde e favorecendo o trabalho integrado, e não apenas partilhado. E é por meio das equipes da ABS que as responsabilidades sobre o cuidado se manifestam de forma veemente, já que são estas as gestoras de seus projetos terapêuticos, dos vínculos e dos cuidados ao usuário por meio de referências e contrarreferências vinculadas ao Sistema Único de Saúde ${ }^{19,21}$, como afirma um docente: 
O PSF parece que veio pra cuidar de populações mais carentes [...] não é medicina para pobres, mas é uma reorganização da visão de que as pessoas são mais bem cuidadas quando têm uma referência em suas vidas. (E1P1)

Na perspectiva da integralidade, a Atenção Básica em Saúde organiza os processos de trabalho em uma assistência multiprofissional baseada em diretrizes, como o acolhimento e o vínculo, por meio de equipes responsáveis pelo cuidado vinculado aos atos assistenciais primitivos da clínica que reservem atos diagnósticos e terapêuticos de maior complexidade para reais funções do cuidado ao paciente ${ }^{19}$ :

O PSF é um grande avanço dentro da saúde pública no Brasil; ele aproxima o médico da população, aumenta esse vínculo entre o médico e as pessoas [...] Aumentase a responsabilidade e a confiança. (M1P1)

Na reorganização da clínica do cuidado, três conceitos devem orientar o processo de trabalho guiado pela diretriz da integralidade: a clínica ampliada, a democratização da gestão (sistema de cogestão) e a integração dos diversos pontos de conexão de um sistema público de saúde. Em termos genéricos, esta é a concepção de Paideia ${ }^{22}$. Tal concepção aposta numa estratégia organizacional e noutra concepção de gestão do trabalho clínico, supondo que o interesse corporativo dos profissionais não prevalecerá sobre seu compromisso com o usuário e com a organização do trabalho, reconstruindo a clínica segundo um "neoartesanato" de responsabilidades macro e microssanitárias. Com isso, reformula-se o modelo biomédico, ao trazer para a prática clínica saberes da Saúde Coletiva, do Planejamento e da Gestão, das Ciências Sociais e Políticas, envolvendo os trabalhadores e usuários na reforma e reorganização do modo de fazer sob a ótica da gestão participativa ${ }^{22}$.

A clínica ampliada se baseia na construção de responsabilidade singular e de vínculo estável entre equipe de saúde e paciente, remetendo ao conceito do profissional de referência, que se torna um instrumento importante na reconstrução da clínica do cuidado ${ }^{22}$, como afirma um docente que destaca o papel da ABS no contexto do SUS: "nós temos que resolver no mínimo $80 \%$ da demanda apresentada, e o que sobra nós vamos encaminhar para um serviço especializado, com tecnologia dura" (E1P1).

\section{O papel do SUS na formação profissional de novos sujeitos}

A finalidade de qualquer ação em saúde é produzir o cuidado, que é marcado por distintos modos tecnológicos de operar este ato, a partir do arranjo entre dimensões materiais e não materiais do ato de fazer saúde ${ }^{23}$.

Estas dimensões se expressam em terrenos tecnológicos de domínios leve, leve-duro e duro (tecnologia dura é entendida como a de equipamentos e máquinas; leve-dura, como a de saberes tecnológicos clínicos e epidemiológicos; leve, como a de modos relacionais de agir na produção dos atos de saúde) ${ }^{23}$. O modelo, cujo sentido é dado pelo mundo das necessidades dos usuários, deve ser centrado fundamentalmente nas tecnologias leves e leve-duras, ao contrário da predominante hoje, cujo sentido é dado pelos interesses corporativos e financeiros das indústrias de equipamentos.

Logo, devem-se produzir interações positivas entre o agir tecnológico e a lógica das necessidades de saúde dos usuários, individuais e coletivas ${ }^{23}$. Esta organização do trabalho remete o estudante a um modelo biomédico contextualizado com as reais necessidades da população. Um deles ressalta o papel inovador que a UPP desempenha em sua formação: “Os alunos terão uma visão mais próxima da medicina real, a medicina fora da academia, longe da tecnologia, protegida pelo hospital, pelo exame complementar" (E6P1).

Este modelo de cuidado é centrado nas diretrizes do acolhimento, vínculo/responsabilização e autonomização. Entendemos o acolhimento como a possibilidade de universalizar o acesso do usuário, assim como a escuta, que qualifica o usuário e o compromisso com a resolução de seu problema de saúde. $\mathrm{O}$ vínculo se baseia no estabelecimento de referências entre a equipe de trabalhadores e os usuários na produção do cuidado $^{20}$. A fala docente demonstra a importância do vínculo na construção de saberes e práticas:

\footnotetext{
É a possibilidade que eles têm de fazer uma reflexão sobre a prática e aprender a criar vínculo, ser ético, ser responsável, ter compromisso, ter uma visão sobre todas as dimensões do paciente, aprender a trabalhar com a equipe multiprofissional. (M4P1)
}

A autonomização significa a autonomia do usuário para viver sua vida. Caracteriza-se pelo aumento da capacidade dos usuários para compreenderem e atuarem sobre si mesmos por meio do autocuidado e da compreensão do processo saúde-enfermidade, bem como da capacidade de usar o próprio poder e estabelecer compromisso e contrato com outros ${ }^{20}$.

No cenário da USF, os estudantes aprendem a conhecer este modelo de atenção afastados do modelo hegemônico, hospitalocêntrico, de tecnologias duras e estruturas fechadas, para se inserirem na descoberta da complexidade do ser humano, por meio de tecnologias leves, e identificarem o valor 
da relação profissional-usuário no cuidado das necessidades de saúde ${ }^{24}$. A fala seguinte remete a uma visão humanística do novo profissional de saúde, que desfaz o foco biológico de seu paciente perante a realidade em saúde em que se insere durante a sua formação:

Só identificamos por que as pessoas estão adoecendo se formos até a casa delas [...] é diferente da proteção do consultório; e se os alunos forem na visita e se depararem com essa realidade, isso vai mobilizar sua função cognitiva, afetiva, e ajudá-los a ver a complexidade do ser humano. (E4P1)

Esta experiência educacional, inserida no cenário real da prática em saúde, desenvolve nos estudantes competências e habilidades essenciais à sua atuação - como postura profissional, comunicação interpessoal, valorização do contexto dos pacientes, relações éticas e trabalho em equipe -, além de manter a atenção destes voltada às necessidades de saúde reais da comunidade ${ }^{25}$, o que é exemplificado a seguir:

Procuramos inseri-lo dentro da equipe [...] isso favorece esse fator de ensino-aprendizagem [...] aprendendo juntos, nós estamos construindo conhecimento juntos, a gente identifica necessidades, eles criam questões de aprendizagem, isso é discutido, eles vão fazer buscas, treinam e aplicam isso. (M4P2)

Os professores reconhecem o desejo de muitos estudantes, notadamente os de Medicina, de serem especialistas e atuarem em cenários distanciados das necessidades da sociedade, como consultórios particulares e espaços hospitalares. Mas ilustram a necessidade de estes valorizarem os diversos níveis da atenção do SUS e, assim, contribuírem na construção plena do sistema:

Mesmo que ele não vá trabalhar na atenção primária, isso ele vai levar pra todos os outros níveis de atenção, formando um novo olhar para aquela pessoa que está ali, não à doença, não a um número. (E4P1)

\section{O papel do docente na construção profissional de novos sujeitos}

Ao se estabelecer um currículo inovador que possibilite a aprendizagem nos cenários descritos, é preciso vencer a grande resistência dos educadores, notadamente docentes médicos, de referência tradicional de ensino-aprendizagem (cujo paradigma é flexneriano e foca a doença e a transmissão de conhecimentos por meio de aulas expositivas e avaliações que privilegiam a dimensão cognitiva e fragmentada) ${ }^{26}$.
Em contrapartida, o enfoque pedagógico moderno enfatiza os aspectos de formação médica, que envolve competências, habilidades e atitudes; dedica-se menos aos domínios do conhecimento puramente teórico e volta-se para o desenvolvimento psicomotor realmente relevante nesta formação ${ }^{26}$. Esta preocupação é expressa pelas falas dos docentes, que se instrumentalizam para facilitar a aprendizagem e o ensino:

\footnotetext{
“Nós provocamos no estudante a oportunidade de buscar, de questionar, de indagar, e isto são destrezas, capacidades muito necessárias para os dias de hoje, alguns anos atrás a transmissão bastava" (M5P2).
}

Trata-se do novo paradigma da integralidade, que capacita o profissional a identificar e lidar com os problemas do processo saúde-doença em todo o seu contexto, equilibrando o nível técnico com a atenção às questões sociais e comportamentais. Naturalmente, o desenvolvimento deste novo modelo se apoia em atividades realizadas nos cenários de prática clínica real ${ }^{26}$.

Na docência, o enfoque se torna semelhante. Espera-se que o docente da saúde não seja um profundo especialista, fragmentado e impositivo, mas tenha uma formação docente baseada em processos de reflexão e motivação para a busca de informações, e que propicie aos estudantes a construção de conhecimentos compatíveis com a solução de problemas, numa perspectiva ampla e humana.

Assim, esse professor deve estimular a crítica, a reflexão, e oferecer a oportunidade de reconstruir o ensino em direção às reais necessidades da sociedade ${ }^{4}$. A fala seguinte caracteriza um novo papel do educador na aprendizagem, que se torna significativa e motivante:

Um grande desafio é tentar organizar situações, permitir que o estudante aprenda e não apenas ensine [...] nosso papel é tentar ajudá-los a perceber o quanto eles sabem e tentar construir um pouco mais. (M5 P1)

A atuação do docente deve estimular a problematização, a busca de informações, leituras, reflexões e encorajar os estudantes a colocar em prática as propostas de enfrentamento das situações, a partir da realidade em que se inserem: "O facilitador facilita a inserção, a construção do conhecimento e facilita a atuação de toda a equipe" (M4P2).

Neste processo educacional, muitos professores são os próprios médicos ou enfermeiros da rede básica de saúde. Por isso, sua inserção no processo de ensino-aprendizagem necessita de capacitações permanentes para que os mesmos possam facilitar esse processo de forma adequada. A capacitação ocor- 
re semanalmente, denomina-se Educação Permanente (EP) e proporciona a estes profissionais a didática necessária para que facilitem o processo educacional da UPP.

A Educação Permanente os tem auxiliado a repensar suas práticas docentes, uma vez que os insere em um novo processo educacional, baseado não mais na transmissão de conhecimentos, mas na construção significativa de uma teia de saberes ${ }^{27}$ :

A EP tem um papel importantíssimo nesse processo, no sentido de auxiliar quem está neste papel de facilitador a trabalhar uma mudança de atitude, em ser muito mais um professor perguntador do que um professor informador, e ajudar o estudante a unir as coisas que ele sabe, construir um corpo de conhecimento. (E5P2)

A EP integra a reflexão crítica às práticas destes profissionais no processo de ensino-aprendizagem, insere essas práticas em fluxos de reflexão crítica do fazer ${ }^{27}$, e isto faz o profissional repensar suas práticas tanto como facilitador quanto como profissional da ABS:

Eu já me peguei na UPP inteira prescrevendo e atendendo um monte de demandas da unidade de saúde, até perceber o meu papel naquele momento. E graças às EPs pude entender que não era meu papel ser o médico naquele momento. (E2P2)

Assim, o papel do docente na construção profissional de novos sujeitos se dá pela forma inovadora de assistir o processo de ensino-aprendizagem, facilitando a construção emancipadora do saber e das práticas voltadas para um estudante participativo, questionador de seu próprio saber e que tenha seu processo de aprendizagem voltado para as necessidades da comunidade.

\section{CONSIDERAÇÕES FINAIS}

O estudante de graduação necessita de uma estrutura educacional que facilite o trânsito entre prática e teoria. A Unidade de Prática Profissional se presta a este propósito.

Como mediadores fundamentais dessa relação, os docentes devem ser capacitados para esse novo processo de aprendizagem. O papel do docente é o de um grande facilitador, e o contato prolongado e horizontalizado com o mesmo professor deve ser estimulado, a fim de formar melhores vínculos entre o facilitador e o estudante quando este inicia sua formação profissional na área de saúde.

A formação não se restringirá ao cenário da ABS, pois o estudante deve construir outros conhecimentos ao longo da graduação. Contudo, este aprendizado no cenário da ABS desde o início do curso se diferencia do aprendizado de outros estudantes pelos vínculos que os alunos estabelecem e pela formação crítico-reflexiva que desenvolvem ao aprender a aprender com a realidade em que se inserem.

Considera-se fundamental o papel da ABS na formação dos profissionais de saúde, destacando-se o papel transformador e emancipador que o docente exerce nessa formação, munido da orientação necessária e contínua dos passos de sua tarefa educacional, a Educação Permanente. Esta, ao mesmo tempo em que os dirige nessa tarefa de construção do saber, lhes traz o repensar de seu processo de trabalho e linha de cuidado, enquanto profissionais de saúde na ABS.

Portanto, evidencia-se o desafio de incentivar novas experiências, como a da Famema, bem como a constante (re)construção da UPP, a fim de torná-la ainda mais responsável nos processos de mudança da educação dos profissionais de saúde.

\section{REFERÊNCIAS}

1. Piancastelli CH. Saúde da família e formação de profissionais de saúde. In: Arruda BKG, org. A educação profissional em saúde e a realidade social. Recife: Instituto Materno Infantil de Pernambuco:MS; 2001. p.121-40.

2. Machado MFAS, Monteiro EMLM, Queiroz DT, Vieira NFC, Barroso MGT. Integralidade, formação de saúde, educação em saúde e as propostas do SUS: uma revisão conceitual. Ciênc Saude Coletiva. 2007;12(2):335-42.

3. Ceccim RB, Feuerwerker LCM. O quadrilátero da formação para a área da saúde: ensino, gestão, atenção e controle social. Physis. 2004;14(1):41-65.

4. Costa NMSC. Docência no ensino médico: por que é tão difícil mudar? Rev Bras Educ Med 2007;31(1):21-30.

5. Ceccim RB. Educação permanente em saúde: desafio ambicioso e necessário. Interface Comum Saúde Educ. 2005;9(16):161-77.

6. Feuerwerker LCM. Além do discurso de mudança na educação médica: processos e resultados. São Paulo: Hucitec; 2002.

7. Brasil. Ministério da Educação. Conselho Nacional de Educação. Resolução CNE/CES nº 4, de 07 de novembro de 2001. Institui diretrizes curriculares nacionais do curso de graduação em medicina. Diário Oficial da União. Brasília, 9 nov. 2001; Seção 1, p.38.

8. Brasil. Ministério da Saúde. Ministério da Educação. Organização Panamericana da Saúde. PROMED: Programa de incentivo a mudanças curriculares nos cursos de medicina. Brasília: Secretaria de Políticas da Saúde; 2002. [Edital de Convocação]. 
9. Ministério da Saúde. [homepage]. Brasília:MS; 2005[acesso em 4 ago. 2007]. Programa nacional de reorientação da formação profissional em saúde PRÓ-SAÚDE; [aproximadamente 1 tela]. Disponível em: http://portal/ sgtes/visualizar_texto.cfm?idtxt=22848

10. Dellors J, Mufti I, Amagi I, Carneiro R, Chung F, Geremek B. Educação: um tesouro a descobrir. São Paulo: Cortez; 2000.

11. Feuerwerker LCM, Costa H, Rangel ML. Diversificação de cenários de ensino e trabalho sobre necessidades: problemas da comunidade. Divulg Saúde Debate. 2000;22:36-48.

12. Campos GWS. Papel da rede de atenção básica em saúde na formação médica: diretrizes: documento preliminar. Rio de Janeiro: ABEM; 2005.

13. Faculdade de Medicina de Marília. Necessidade de saúde 1 e prática profissional: $1^{\underline{a}}$ série: cursos de medicina e enfermagem. Marília: Famema; 2007.

14. Tyler RW. Princípios básicos de currículo e ensino. Porto Alegre: Globo; 1976.

15. Silva RF. Prática educativa transformadora: a trajetória da Unidade Educacional. São Paulo; 2000. Doutorado [Tese] - Universidade de São Paulo.

16. Richardson RJ. Pesquisa social: métodos e técnicas. São Paulo: Atlas; 1999.

17. Tobar F, Yalour MR. Como fazer teses em saúde pública: conselhos e idéias para formular projetos e redigir teses e informes de pesquisa. Rio de Janeiro: Fiocruz; 2001.

18. Minayo MCS. O desafio do conhecimento: pesquisa qualitativa em saúde. São Paulo: Hucitec; 1993.

19. Franco TB, Magalhães Jr HM. Integralidade na assistência a saúde: a organização das linhas do cuidado. In: Merhy EE, Magalhães Junior HM, Rimoli J, Franco TB. O trabalho em saúde: olhando e experienciando o SUS no cotidiano. São Paulo: Hucitec; 2007. p.125-33.

20. Franco TB, Merhy EE. Programa de Saúde da Família (PSF): contradições de um programa destinado à mudança do modelo tecnoassistencial. In: Merhy EE, Magalhães Junior HM, Rimoli J, Franco TB. O trabalho em saúde: olhando e experienciando o SUS no cotidiano. São Paulo: Hucitec; 2007. p. 55-124.

21. Ministério da Saúde. Departamento de Atenção Básica. Guia prático do programa de saúde da família. Brasília: Ministério da Saúde; 2001.
22. Campos GWS, Amaral MA. A clínica ampliada e compartilhada, a gestão democrática e redes de atenção como referenciais teórico-operacionais para a reforma do hospital. Ciênc Saude Coletiva. 2007;12(4):849-59.

23. Merhy EE. Um dos grandes desafios para os gestores do SUS: apostar em novos modos de fabricar os modelos de atenção. In: Merhy EE, Magalhães Junior HM, Rimoli J, Franco TB. O trabalho em saúde: olhando e experienciando o SUS no cotidiano. São Paulo: Hucitec; 2003. p.15-35.

24. Ferreira RC, Silva RF, Aguera CB. Formação do profissional médico: a aprendizagem na atenção básica de saúde. Rev Bras Educ Med 2007; 31(1):52-9.

25. Ferreira RC, Zanolli MB. Relações éticas na atenção básica em saúde: a vivência dos estudantes de medicina. Ciênc Saude Coletiva [periódico na Internet] 2007. [acesso em 22 jan. 2007]; 12(4): 849-59. Disponível em: http:/ / www.scielo.br/pdf/csc/v12n4/04.pdf

26. Blank D. A propósito de cenários e atores: de que peça estamos falando? Uma luz diferente sobre o cenário da prática dos médicos em formação. Rev Bras Educ Med. 2006;30(1):27-31.

27. Ceccim RB. Educação permanente em saúde: descentralização e disseminação de capacidade pedagógica na saúde. Ciênc Saude Coletiva. 2005;10(4):975-86.

\section{CONTRIBUIÇÃO DOS AUTORES}

Os autores participaram de forma equânime e suficiente na concepção e desenho do estudo, assim como da análise e interpretação dos dados e da redação deste texto.

\section{CONFLITO DE INTERESSES}

Declarou não haver

\section{ENDEREÇO PARA CORRESPONDÊNCIA}

Faculdade de Medicina de Marília - Famema Ricardo Corrêa Ferreira

Av. Monte Carmelo, 800

Fragata - Marília

CEP 17519-030 - SP

E-mail: riguaira@famema.br 